\title{
Controle fitopatológico do Fusarium subglutinans pelo óleo essencial do capim- citronela (Cymbopogon nardus L.) e do composto citronelal
}

\author{
SEIXAS, P.T.L. ${ }^{*}$; CASTRO, H.C. ${ }^{1}$; SANTOS, G.R. ${ }^{1}$; CARDOSO, D.P. ${ }^{1}$ \\ ${ }^{1}$ Universidade Federal do Tocantins, Curso de Agronomia, CP 66, CEP 77.402-970, Gurupi - Tocantins - Brasil \\ *agronomapaula@hotmail.com
}

\begin{abstract}
RESUMO: Este trabalho teve como objetivo avaliar o efeito fungitóxico do óleo essencial de capim-citronela e do seu constituinte majoritário citronelal sobre a inibição micelial do fitopatógeno Fusarium subglutinans, agente causal da fusariose da cultura do abacaxi (Ananas comosus). Para avaliar o efeito do óleo essencial no crescimento micelial do fungo, foram utilizadas seis alíquotas $(0,5,10,15,20$ e 25 ì $)$ do óleo e do citronelal que foram distribuídas na superfície do meio BDA (batata-dextrose-ágar) antes da repicagem do fungo. O crescimento micelial foi medido após 48 h de instalação do experimento e em cinco épocas de avaliação (2, 4, 6, 8 e 10 dias após repicagem). Os resultados indicaram que o óleo essencial do capim-citronela demonstrou maior efeito inibitório do crescimento micelial do fungo F. subglutinans do que o composto citronelal. Em todas as alíquotas utilizadas o óleo essencial proporcionou menor taxa de crescimento micelial do que o citronelal.
\end{abstract}

Palavras-chave: Cymbopogon nardus, planta medicinal, bioatividade

\begin{abstract}
Fungitoxic activity of essential oil of citronella grass (Cymbopogon nardus L.) and compound citronellal. This study aimed to evaluate the fungitoxic effect of the essential oil of citronella grass and its major constituent citronellal on the inhibition of mycelial pathogen Fusarium subglutinans, the causal agent of Fusarium culture of pineapple (Ananas comosus). To evaluate the effect of essential oil in the mycelial growth of the fungus were used six rates $(0,5$, $10,15,20$ and $25 \mathrm{~mL}$ ) of oil that were distributed on the surface of PDA medium (potato dextrose agar) before subculturing of the fungus. Mycelial growth was measured after $48 \mathrm{~h}$ of the experiment and five times of assessment (2, 4, 6, 8 and 10 days after subculturing). The results indicated that the essential oil of citronella grass showed higher inhibitory effect of mycelial growth of the fungus F. subglutinans than compound citronellal. In all rates used of the essential oil gave lower growth rate than the mycelial citronellal.
\end{abstract}

Key words: Cymbopogon nardus, medicinal plant, bioactivity.

\section{INTRODUÇÃO}

O controle químico de fitopatógenos utilizado intensivamente nas últimas décadas vem criando inúmeros problemas, tais como: resistência microbiana adquirida, contaminação ambiental (água, solo, produtor e consumidor) e elevação dos custos de produção. O controle alternativo com as plantas medicinais está sendo atualmente estudado, em função de não apresentarem risco ambiental, serem geralmente inócuas aos animais e seres humanos, bem como apresentar menor custo (Moreira et al., 2008).

Óleos essenciais são produtos aromáticos de metabolismo secundário de plantas, normalmente produzidos por células secretoras ou grupos de células, sendo encontrados em diversas partes do vegetal, como folhas e talos (Scherer et al., 2009). Vários estudos têm comprovado o efeito de compostos extraídos de óleos essenciais de plantas que atuam como fungicidas naturais inibindo a atividade fúngica e, um número significativo destes constituintes tem se mostrado eficaz (Chao \& Young, 2000). A exploração da bioatividade antimicrobiana e/ou elicitora de defesa utilizando compostos secundários presentes em óleos essenciais de plantas medicinais constitui-se em mais uma forma potencial para controle de doenças em plantas cultivadas (Carvalho

Recebido para publicação: agosto de 2011

Aceito para publicação: dezembro de 2011

Rev. Bras. PI. Med., Botucatu, v.13, especial, p.523-526, 2011. 
et al., 2008).

As plantas medicinais possuem compostos secundários que tanto podem ter ação fungitóxica (ação antimicrobiana direta) (Schwan-Estrada et al., 2003) e como elicitora, ativando mecanismos de defesa nas plantas (ação indireta) (Schwan-Estrada \& Stangarlin, 2005). Na literatura, é possível encontrar vários trabalhos que utilizam as propriedades antimicrobianas dos compostos secundários de plantas medicinais para o controle de agentes fitopatogênicos. O geraniol encontrado no óleo do capim-citronela e no óleo de palmarosa tem sido relatado como um composto de elevada atividade antimicrobiana (Jirovetz et al., 2007; Duarte et al., 2007), assim como os compostos citronelal e citronelol encontrados no óleo do capim-citronela (Sato et al., 2006; Kordali et al., 2007).

A cultura do abacaxi (Ananas comosus) é atacada por diversas doenças nas diferentes regiões produtoras do mundo tanto em condições de campo quanto em pós-colheita. De todas as doenças que afetam o abacaxizeiro no Brasil, a fusariose, causada pelo fungo Fusarium subglutinans é a mais destrutiva, incitando perdas significativas à produção de frutos (Matos et al., 2009; Zacaroni et al., 2009).

O Cymbopogon nardus L. Rendle (capimcitronela), planta originada do Ceilão e da Índia, pertence á família Poaceae, subfamília Panicoideae. O gênero Cymbopogon é constituído de oitenta e cinco espécies. O C. nardus apresenta constituição do óleo essencial com dois compostos majoritários o citronelal e o geraniol (Castro et al., 2007).

Este trabalho teve como objetivo avaliar a atividade antifúngica do óleo essencial do capimcitronela e do seu composto majoritário o citronelal, sobre a inibição do crescimento micelial do fungo Fusarium subglutinans, isolado da cultura do abacaxi.

\section{MATERIAL E MÉTODO}

O experimento foi conduzido no Laboratório de Fitopatologia, do Câmpus Universitário de Gurupi, Universidade Federal do Tocantins - UFT. As coordenadas geográficas locais de referência são $11^{\circ}$ $43^{\prime} S$ de latitude e $49^{\circ} 04^{\prime} \mathrm{W}$ de longitude e $300 \mathrm{~m}$ de altitude. A exsicata da amostra do material vegetal foi depositada no herbário da Universidade Federal de Viçosa com o número VIC 30283.

$\mathrm{O}$ isolamento do patógeno foi realizado a partir de frutos oriundos do município de Miranorte TO (pólo de produção regional de abacaxi), com sintomas típicos de fusariose. Os procedimentos de isolamento constaram da desinfestação superficial de fragmentos de tecidos lesionados em solução de hipoclorito de sódio a $5 \%$, por três minutos, lavagem em álcool $70 \%$, por um minuto, e lavagem por três vezes consecutivas em água destilada esterilizada.
Os fragmentos foram acondicionados em placas de Petri contendo o meio nutritivo BDA (Batata-DextroseÁgar). As placas foram incubadas por oito dias, à temperatura de $25 \pm 2^{\circ} \mathrm{C}$ e fotoperíodo de 12 horas.

A extração do óleo essencial foi feita pelo método de hidrodestilação no equipamento Clevenger, com $1000 \mathrm{~mL}$ de água destilada e $100 \mathrm{~g}$ da folha desidratada do capim-citronela, por um período de 2 horas. Ao final, coletou-se o óleo essencial de citronela (sobrenadante) com auxílio de uma pipeta, e posteriormente armazenou-se em frascos de vidro protegidos da luz envolto com papel alumínio. O composto citronelal foi adquirido na forma pura. Para verificar o efeito do óleo essencial sobre o crescimento micelial, alíquotas de 0, 5, 10, 15, 20 e 25 ì do óleo essencial e do citronelal, foram colocados no centro de placas de Petri contendo BDA e distribuídos sobre a superfície do meio de cultura com auxílio da alça de Drigalsky. Em seguida, um disco de $6 \mathrm{~mm}$ de diâmetro contendo micélio de $F$. subglutinans com cerca de 8 dias de idade em BDA, foi repicado para o centro das placas, vedadas com filme plástico e mantidas a $25^{\circ} \mathrm{C} \pm 2^{\circ} \mathrm{C}$ em B.D.O. Na testemunha não se adicionou nenhum tipo de produto ao meio de cultura. As avaliações foram realizadas por medições, após 48 horas da instalação do experimento e depois a cada dois dias, usando-se paquímetro digital para medir o diâmetro das colônias, totalizando cinco épocas de avaliação.

O delineamento experimental foi inteiramente casualizado, com quatro repetições, sendo as médias comparadas pelo teste de Tukey a $5 \%$ de probabilidade. As equações de regressão foram ajustadas com base no teste t dos coeficientes e no coeficiente de determinação. As análises estatísticas foram realizadas no programa SAEG (Ribeiro Júnior \& Melo, 2009).

\section{RESULTADO E DISCUSSÃO}

Os tratamentos com capim-citronela e citronelal propiciaram redução do crescimento micelial in vitro do fungo Fusarium subglutinans. O óleo essencial do capim-citronela nas alíquotas de 15, 20 e $25 \mu \mathrm{L}$ aos 2 e 4 DAR (dias após repicagem) apresentaram $100 \%$ de inibição do crescimento micelial do patógeno (Tabela 1). Nas épocas de avaliação realizadas aos 6,8 e 10 DAR o óleo essencial do capim-citronela nas alíquotas de 15 a $25 \mu \mathrm{L}$ diferiram estatisticamente dos outros tratamentos, apresentando maior efeito de inibição do crescimento micelial. De acordo com as equações de regressão ajustadas foi observado uma taxa de crescimento micelial na alíquota de $25 \mu \mathrm{L}$ do óleo essencial de citronela de $1,5518 \mathrm{~mm} \mathrm{dia}^{-1}$, atingindo $11,25 \mathrm{~mm}$ na última época de avaliação. A testemunha apresentou taxa de crescimento micelial de 8,5605

Rev. Bras. Pl. Med., Botucatu, v.13, especial, p.523-526, 2011. 
$\mathrm{mm}$ dia $^{-1}$, atingindo na última época de avaliação crescimento micelial de $89,70 \mathrm{~mm}$ (Tabela 1 ).

Resultados semelhantes foram alcançados com óleo essencial de Ocimum gratissimum nas doses de 20, 40 e $60 \mu \mathrm{L}$, que inibiram totalmente 0 crescimento micelial in vitro dos fungos Rhizoctonia solani, Sclerotium rolfsii, Phytophthorasp. e Alternaria alternata (Benini et al., 2010).

Segundo Diniz et al. (2008) verificaram a ação fungicida do óleo de Mentha arvensis L. com a alíquota de $100 \mu \mathrm{L}$ na inibição de $100 \%$ no crescimento micelial dos fungos Aspergillus sp., Penicillum rubrum e Fusarium moniliforme, comprovando a eficácia do uso de óleo essencial no controle de patógenos in vitro.

Pereira et al. (2011), observaram que doses a partir de $1000 \mu \mathrm{L} \mathrm{L}^{-1}$ dos óleos essenciais de canela (Cinnamomum zeylanicum), tomilho (Thymus vulgaris), erva-cidreira (Lippia alba) e capim-citronela (Cymbopogon nardus), inibiram completamente a germinação de conídios de Cercospora coffeicola, enquanto o óleo de cravo-da-índia (Sizygium aromaticum) e árvore de chá (Melaleuca alternifólia) inibiram completamente a germinação de conídios a partir de 1500 e $2000 \mu \mathrm{L} \mathrm{L}^{-1}$, respectivamente. Da mesma forma Rozwalka et al. (2008) verificaram que o óleo essencial de capim-limão (Cymbopogon citratus) apresentou atividade antifúngica sobre o desenvolvimento micelial de Colletotrichum gloeosporioides. Lima et al. (2008) relataram a eficiência do óleo essencial de capim-citronela (Cymbopogon nardus L.) no controle da ramulose
(Colletotrichum gossypii) na cultura do algodão (Gossypium hirsutum L.).

De acordo com Amaral \& Bara (2005), os óleos essenciais, possivelmente atuam na parede celular dos fungos, causando o vazamento do conteúdo celular. E esse efeito também foi observado mais tarde por Rasooli et al. (2006), usando microscopia eletrônica de transmissão, onde o óleo essencial de Thymus eriocalyx promoveu danos severos para as paredes, membranas e organelas celulares de Aspergillus niger. O mecanismo de ação dos monoterpenos envolve, principalmente, efeitos tóxicos à estrutura e à função da membrana celular (Oliveira et al., 2011).

Em relação ao composto citronelal foi observado $100 \%$ de inibição do crescimento micelial do fungo nas alíquotas de 15, 20 e $25 \mu \mathrm{L}$ na primeira época de avaliação. Na última época de avaliação (10 DAR), as alíquotas de 15 a $25 \mu \mathrm{L}$ diferiram estatisticamente das outras alíquotas. Na alíquota de $25 \mu \mathrm{L}$ do composto citronelal observou-se uma taxa de crescimento micelial do fungo de $3,362 \mathrm{~mm}$ dia $^{-1}$, atingindo na última época de avaliação 24,48 $\mathrm{mm}$ (Tabela 1).

O maior efeito de inibição do óleo essencial do capim-citronela no crescimento micelial do fungo Fusarium subglutinans em relação ao composto citronelal pode estar relacionado com a interação dos vários compostos constituintes do óleo essencial. Desta forma, o maior efeito de inibição do óleo essencial é devido ao sinergismo existente entre os compostos do óleo essencial do capim-citronela, que

TABELA 1. Valores médios, equações de regressão e coeficiente de determinação $\left(r^{2}\right)$ do crescimento micelial $(\mathrm{mm})$ do fungo Fusarium subglutinans, em seis alíquotas $(A \mathrm{~L})\left(\mathrm{A}_{1}=0 ; \mathrm{A}_{2}=5 \mu \mathrm{L} ; \mathrm{A}_{3}=10 \mu \mathrm{L} ; \mathrm{A}_{4}=15 \mu \mathrm{L} ; \mathrm{A}_{5}=20 \mu \mathrm{L}\right.$ e $A_{6}=25 \mu \mathrm{L}$ ) do óleo essencial do capim-citronela e do citronelal, em cinco épocas de avaliação.

\begin{tabular}{|c|c|c|c|c|c|c|c|}
\hline \multirow[b]{2}{*}{$A L$} & \multicolumn{5}{|c|}{$\begin{array}{c}\text { Épocas de avaliação } \\
\text { DAR (dias após repicagem) }\end{array}$} & \multirow[b]{2}{*}{ Equações de regressão } & \multirow[b]{2}{*}{$r^{2}$} \\
\hline & 2 & 4 & 6 & 8 & 10 & & \\
\hline \multicolumn{8}{|c|}{ Óleo essencial } \\
\hline $\mathrm{A} 1$ & $20,27 a$ & $39,52 \mathrm{a}$ & $56,23 \mathrm{a}$ & $71,26 \mathrm{a}$ & $90,00 \mathrm{a}$ & $\mathrm{Y}=4,0915+8,5605 \mathrm{EP}$ & $0,9862^{\star \star}$ \\
\hline A2 & $6,52 \mathrm{~b}$ & $14,43 \mathrm{~b}$ & $25,45 \mathrm{~b}$ & $39,32 \mathrm{~b}$ & $56,39 \mathrm{~b}$ & $Y=-8,9665+6,2310 E P$ & $0,9144^{* *}$ \\
\hline A3 & $0,00 \mathrm{~b}$ & $7,59 \mathrm{bc}$ & $14,38 \mathrm{c}$ & $23,15 \mathrm{c}$ & $36,30 \mathrm{c}$ & $Y=-10,1663+4,4081 E P$ & $0,9178^{* *}$ \\
\hline A4 & $0,00 \mathrm{~b}$ & $0,00 \mathrm{c}$ & $5,81 \mathrm{~d}$ & $8,49 \mathrm{~d}$ & $13,77 \mathrm{~d}$ & $Y=-5,1945+1,8013 E P$ & $0,8829^{* *}$ \\
\hline A5 & $0,00 \mathrm{~b}$ & $0,00 \mathrm{c}$ & $6,66 \mathrm{~d}$ & $8,88 d$ & $12,03 \mathrm{~d}$ & $Y=-4,3678+1,6466 \mathrm{EP}$ & $0,9103^{* *}$ \\
\hline A6 & $0,00 \mathrm{~b}$ & $0,00 \mathrm{c}$ & $5,82 \mathrm{~d}$ & $8,02 \mathrm{~d}$ & $11,60 \mathrm{c}$ & $Y=-4,2730+1,5518 E P$ & $0,4977^{* *}$ \\
\hline \multicolumn{8}{|c|}{ Citronelal } \\
\hline $\mathrm{A} 1$ & $20,71 \mathrm{a}$ & $43,46 \mathrm{a}$ & $63,21 \mathrm{a}$ & $74,25 \mathrm{a}$ & $90,00 \mathrm{a}$ & $Y=4,0915+8,5605 E P$ & $0,9862^{\star \star}$ \\
\hline A2 & $7,43 a b$ & $21,91 \mathrm{~b}$ & $37,73 \mathrm{~b}$ & $52,19 \mathrm{~b}$ & $67,22 \mathrm{~b}$ & $Y=-7,6593+7,4934 E P$ & 0,9640 ** \\
\hline A3 & $3,38 b$ & $16,16 \mathrm{bc}$ & $29,25 \mathrm{bc}$ & $42,87 \mathrm{bc}$ & $58,05 \mathrm{~b}$ & $Y=-10,8833+6,8034 E P$ & $0,9781^{* *}$ \\
\hline A4 & $0,00 \mathrm{~b}$ & $10,38 \mathrm{bc}$ & $19,15 \mathrm{~cd}$ & $30,33 \mathrm{~cd}$ & $39,33 \mathrm{c}$ & $Y=-9,7458+4,9301 E P$ & $0,9285^{\star *}$ \\
\hline A5 & $0,00 \mathrm{~b}$ & $6,01 \mathrm{c}$ & $16,26 \mathrm{~cd}$ & 26,72 de & $40,76 \mathrm{c}$ & $Y=-12,7188+5,1114 E P$ & $0,9359^{* *}$ \\
\hline A6 & $0,00 \mathrm{~b}$ & $3,58 \mathrm{c}$ & $8,25 \mathrm{~d}$ & $15,78 \mathrm{e}$ & $27,52 \mathrm{c}$ & $Y=-9,1485+3,3623 E P$ & $0,6841^{* *}$ \\
\hline
\end{tabular}

Rev. Bras. PI. Med., Botucatu, v.13, especial, p.523-526, 2011. 
atuam de forma conjunta, o que propiciou um maior efeito fungistático do que o composto citronelal.

A pesquisa com plantas medicinais como fonte de defensivos naturais é promissora, com possibilidade de novas e relevantes descobertas. Entretanto, outros estudos devem ser realizados para verificar a viabilidade do uso do óleo essencial do capim-citronela no controle fitossanitário de fungos fitopatogênicos in vivo. O controle fitossanitário a partir dos óleos essenciais pode ser um método eficaz e de baixo impacto ambiental, no combate a organismos patogênico causadores de doenças em diferentes espécies vegetais.

\section{AGRADECIMENTO}

Os autores agradecem o apoio financeiro da CAPES e do CNPq.

\section{REFERÊNCIA}

AMARAL, M.F.Z.J.; BARA, M.T.F. Avaliação da atividade antifúngica de extratos de plantas sobre o crescimento de fitopatógenos. Revista Eletrônica de Farmácia, v.2, n.2, p.5-8, 2005.

BENINI, P.C. et al. Efeito in vitro do óleo essencial e extrato aquoso em Ocimum gratissimun colhido nas quatro estações do ano sobre fitopatógenos. Arquivos Instituto Biológico, v.77, n.4, p.677-83, 2010.

CARVALHO, J.B. et al. Fungitoxicidade de Cymbopogon citratus e Cymbopogon martinii a Colletotrichum gloeosporioides em frutos de pimentão. Revista Brasileira de Plantas Medicinais, v.10, n.1, p.88-93, 2008. CASTRO, H.G. et al. Crescimento, teor e composição do óleo essencial de Cymbopogon nardus L. Revista Brasileira de Plantas Medicinais, v.9, n.4, p.55-61, 2007. CHAO, S.C.;YOUNG, D.C. Screening for inhibitory activity of essential oils ou selected bacteria, fungi and viruses. Journal Essential Oil Research, v.12, n.4, p.856-62, 2000. DINIZ, S.P.S.S. et al. Bioatividade do óleo essencial de Mentha arvensis L. no controle de fungos fitopatógenos. Revista Brasileira de Plantas Medicinais, v.10, n.4, p.911, 2008.

DUARTE, M.C.T. et al. Activity of essential oils from Brazilian medicinal plants on Escherichia coli. Journal of Ethnopharmacology, v.111, n.2, p.197-201, 2007.

JIROVETZ, L. et al. Purity, antimicrobial activities and olfactory evaluations of geraniol/nerol and various of their derivatives. Journal of Essential Oil Research, v.19, n.3, p.288-91, 2007.

KORDALI, S. et al. Screening of antifungal activities of 21 oxygenated monoterpenes in vitro as plant disease control agents. Allelopathy Journal, v.19, n.2, p.373-91, 2007.
LIMA, G.T. et al. Citronella oil inhibits cotton ramulosis in controlled conditions. Pest Technology, v.2, n.1, p.24-7, 2008.

MATOS, A.P. et al. Monitoramento da fusariose em plantios de abacaxi 'perola' conduzidos em sistema de produção integrada no estado do Tocantins. Cruz das Almas: Embrapa Mandioca e Fruticultura tropical, 2009. 37p.

MOREIRA, C.G.A. et al. Caracterização parcial de frações obtidas de extratos de Cymbopogon nardus com atividade elicitora de fitoalexinas em sorgo e soja e efeito sobre Colletotrichum lagenarium. Summa Phytopathologica, v.34, n.4, p.332-7, 2008.

OLIVEIRA, M.M.M. et al. Rendimento, composição química e atividade antilisterial de óleos essenciais de espécies de Cymbopogon. Revista Brasileira de Plantas Medicinais, v.13, n.1, p.8-16, 2011.

PEREIRA, R.B. et al. Potential of essential oils for the control of Brown eye spot in coffee plants. Ciência e Agrotecnologia, v.35, n.1, p.115-23, 2011.

RASOOLI, I.; REZAEI, M.B.; ALLAMEH, A. Growth inhibition and morphological alterations of Aspergillus niger by essential oils from Thymus eriocalyx and Thymus $x$ porlock. Food Control, v.17, n.5, p.359-64, 2006.

RIBEIRO JÚNIOR, J.I.; MELO, A.L.P. Guia prático para utilização do SAEG. Viçosa: Editora UFV, 2009. 287p.

ROZWALKA, L.C. et al. Extratos, decoctos e óleos essenciais de plantas medicinais e aromáticas na inibição de Glomerella cingulata e Colletotrichum gloeosporioides de frutos de goiaba. Ciência Rural, v.38, n.2, p.301-7, 2008.

SATO, K. et al. Antimicrobial effect of transcinnamaldehyde, (-)-perillaldehyde, (-)-citronellal, citral, eugenol and carvacrol on airborne microbes using an airwasher. Biological and Pharmaceutical Bulletin, v.29, n.11, p.2292-4, 2006.

SCHERER, R. et al. Composição e atividade antioxidante e antimicrobiana dos óleos essenciais de cravo-daíndia, citronela e palmarosa. Revista Brasileira de Plantas Medicinais, v.11, n.4, p.442-9, 2009.

SCHWAN-ESTRADA, K.R.F.; STANGARLIN, J.R. Extratos e óleos essenciais de plantas medicinais na indução de resistência. In: CAVALCANTI, L.S.; DI PIERO, R.M.; CIA, P.; PASCHOLATI, S.F.; RESENDE, M.L.; ROMEIRO, R.S. (Ed.). Indução de resistência em plantas a patógenos e insetos. Piracicaba: FEALQ, 2005. p.12532.

SCHWAN-ESTRADA, K. R. F.; STANGARLIN, J. R.; CRUZ, M. E. Uso de plantas medicinais no controle de doenças de plantas. In: CONGRESSO BRASILEIRO DE FITOPATOLOGIA, 36., 2003, Uberlândia. Anais... Uberlândia: SBF, 2003. p.54-6.

ZACARONI, M.L. et al. Potencial fungitóxico do óleo essencial de Piper hispidinervum (pimenta longa) sobre os fungos fitopatogênicos Bipolaris sorokiniana, Fusarium oxysporum e Colletotrichum gloeosporioides. Acta Amazonica, v.39, n.1, p.193-8, 2 